crimination. Typability is excellent with electrophoresis of radiolabelled bacteria, as all strains tested in this study produced a clear radiolabelled protein profile. Reproducibility is comparable with that of other typing methods in which strains to be tested must be labelled and run in the same batch. Comparison between strains is optimal if they are run on the same gel; indeed, two strains of epidemic methicillin resistant $S$ aureus were initially read as different when compared on different gels but when rerun on the same gel were indistinguishable from the other epidemic strains. At present typing by electrophoresis of radiolabelled bacteria relies on comparison with known isolates of epidemic methicillin resistant $S$ aureus, although future computer assisted analysis is planned. Discrimination seems, from this limited number of strains, to be equivalent to that of phage typing for the non-epidemic strains.

Polyacrylamide gel electrophoresis of radiolabelled isolates from the hospital outbreak provided rapid confirmation that an epidemic strain of methicillin resistant $S$ aureus was responsible and thus that urgent control measures were necessary. This outbreak is an example of the increasing problem of methicillin resistant $S$ aureus in London hospitals recently. ${ }^{28}$ The explanation for its fairly short duration is not clear but may be the fact that we treated all patients and staff rather than just those who were culture positive. ${ }^{9}$ The finding that the epidemic strains of methicillin resistant $S$ aureus are indistinguishable by electrophoresis after radiolabelling adds further evidence that they may be essentially one single strain, as has been suggested for isolates found in London and Australia. ${ }^{8} 1011$
We thank Mr G M Rees and Mr S J Edmondson for allowing us to present clinical details of patients under their care. We also thank Professor E M Cooke and Dr R R Marples for help and advice. We are grateful to the Division of Hospital Infection for providing strains for this study.

\section{References}

1 Anonymous. What's to be done about resistant staphylococci? [Editorial]. Lancet 1985;ii: 189-90. 2 Marples RR, Cooke EM. Report of workshop on methicillin-resistant Staphylococcus aureus held at the headquarters of the Public Health Laboratory Service on 8 January 1985. 7 Hosp Infect 1985;6:342-8.

3 Selkon JB, Stokes ER, Ingham HR. The role of an isolation unit in the control of hospital infection with methicillin-resistant staphylococci. J Hosp Infect 1980;1:41-6.

4 Pearman JW, Christiansen KJ, Annear DI, et al. Control of methicillin-resistant Staphylococcus aureus (MRSA) in an Australian metropolitan teaching hospital complex. Med f Aust 1985;142:103-8.

5 Laemmli UK. Cleavage of structural proteins during the assembly of the head of bacteriophage T4. Nature 1970;227:680-5.

6 Kersters K, De Ley J. Classification and identification of bacteria by electrophoresis of their proteins. In: Goodfellow M, Board RG, eds. Microbiological classification and identification. proteins. In: Goodfellow M, Boar

7 Tabaqchali S, Holland D, O'Farrell S, Silman R. Typing scheme for Clostridium difficile: its application in clinical and epidemiological studies. Lancet 1984;i:935-8.

8 Bradley JM, Noone P, Townsend DE, Grubb WB. Methicillin-resistant Staphylococcus aureus in a London hospital. Lancet 1985; i: 1493-5.

9 Bartzokas CA, Paton JH, Gibson MF, Graham R, McLoughlin GA, Croton RS. Control and eradication of methicillin-resistant Staphylococcus aureus on a surgical unit. $N$ Engl $\mathcal{J}$ Med 1984;311:1422-5.

10 Gedney J, Lacey RW. Properties of methicillin-resistant staphylococci now endemic in Australia. Med F A ust 1982;1:448-50.

11 Townsend DE, Ashdown N, Bradley JM, Pearman JW, Grubb WB. "Australian" methicillinresistant Staphylococcus aureus in a London hospital? Med f Aust 1984;141:339-40.

Accepted 13 fune 1986)

\title{
Traditional Chinese acupuncture: a potentially useful antiemetic?
}

\author{
J W DUNDEE, W N CHESTNUTT, R G GHALY， A G A LYNAS
}

\begin{abstract}
Two consecutive studies were undertaken to evaluate the effectiveness of acupuncture as an antiemetic used in addition to premedication with opioids in patients undergoing minor gynaecological operations. In the first study 25 of the $\mathbf{5 0}$ patients underwent acupuncture immediately after premedication with $100 \mathrm{mg}$ meptazinol, the rest receiving the drug alone, and in the second 75 patients were allocated randomly to one of three groups: a group receiving $10 \mathrm{mg}$ nalbuphine and acupuncture, a group receiving premedication and dummy acupuncture, and a group receiving premedication alone. Manual needling for five minutes at the P6 acupuncture point (Neiguan) resulted in a significant reduction in perioperative nausea and vomiting in the 50 patients who underwent acupuncture compared with the 75 patients who received no acupuncture.

These findings cannot be explained, but it is recommended that the use of acupuncture as an antiemetic should be explored further.
\end{abstract}

\section{Introduction}

Despite improvements in anaesthetic techniques perioperative vomiting still remains a problem, particularly in ambulant outpatients, in children, and when an opioid is given before or during anaesthesia. ${ }^{12}$ Antiemetics are of limited value and often cause drowsiness or other side effects. ${ }^{3}$

On a visit to the People's Republic of China one of us (JWD) was impressed by the use of acupressure as prophylaxis against vomiting in early pregnancy. At the antenatal clinic women were instructed to press the point Neiguan (P6), just above the right wrist. This is described as a treatment for hyperemesis gravidarum in an English textbook on acupuncture, ${ }^{4}$ but there is no evidence to support the claim. If it could be applied to anaesthetic practice it would be a nontoxic and inexpensive treatment that might be useful in other fields.

We report on two consecutive studies in which a simple traditional Chinese acupuncture procedure was used in addition to opioid premedication in patients undergoing a minor operation under standard anaesthesia. As far as possible the same criteria were applied to these studies as to the evaluations of recognised antiemetic drugs. ${ }^{356}$

The studies were approved by the local medical ethical research committee, and patients gave verbal consent to participate in studies with premedicants, but no reference was made to nausea or vomiting.

\section{Patients and methods}

All of the patients were fit women aged $16-60$ and weighing $40-80 \mathrm{~kg}$, who were to undergo minor gynaecological operations during the same morning. Two studies were carried out in gynaecological units. In the first $100 \mathrm{mg}$ meptazinol was given intramuscularly as premedication, and in the second $10 \mathrm{mg}$ nalbuphine was given. Half of the 50 patients in the first study

\footnotetext{
Department of Anaesthetics, The Queen's University of Belfast

JW DUNDEE, MD, professor

R G GHALY, FFARCS, lecturer

A G A LYNAS, FFARCS, lecturer

Correspondence to: Professor J W Dundee, Department of Anaesthetics, Whitla Medical Building, 97 Lisburn Road, Belfast BT9 7BL.
} 
underwent five minutes of manual needling of $\mathrm{P} 6$ acupuncture point (Neiguan) immediately after the premedication, and the rest (control group) received the drug alone. In the second study 75 patients were divided into three groups: a control group, an acupuncture group, and a group who underwent five minutes of needling at a dummy point on the lateral elbow crease, which was not on any recognised acupuncture line.

There were 25 patients in each group, patients being allocated randomly. All premedicants were given and all acupuncture performed by the authors.

The antiemetic point at which the acupuncture needle is applied is on the pericardial "meridian," two "cun" (Chinese inches) proximal to the wrist crease between the tendons of palmaris longus and the flexor carpi radialis muscles of the right forearm $1 \mathrm{~cm}$ below the skin. The tip of the acupuncture needle is placed near the median nerve. A cun is equivalent to the distance between the creases of the proximal and distal interphalangeal joints of the flexed index finger or roughly the width of the thumb across the interphalangeal joint. A $1 \cdot 2 \mathrm{~cm} 30$ steel wire gauge stainless steel needle was used and manipulated manually for five minutes. The occurrence of a nonanatomically distributed feeling of heaviness, numbness, or tightness (chi) verified the correct positioning of the needle.

Anaesthesia was induced with methohexitone-nitrous oxide-oxygen with no volatile supplements. Operations lasted seven to 12 minutes. Patients were visited preoperatively at $20,40,60$, and 90 minutes after the drug was given and at the first and sixth hours after the operation. On each occasion the occurrence of nausea alone or of vomiting (with or without nausea) was noted. These assessments were performed by an observer who was unaware of which patients had undergone acupuncture.

With nalbuphine the incidence of preoperative emetic effects was so low that only the postoperative sequelae are reported. The significance of the difference in emetic effects in different series was assessed by the $\chi^{2}$ test with Yates's correction $(\mathrm{df}=2)$ in both studies.

\section{Results}

In both studies the groups were broadly comparable in average age, weight, and duration of anaesthesia. There was no obvious difference in the amount of postoperative ambulation between the groups.

Table I shows that there was less vomiting in patients given meptazinol and acupuncture compared with meptazinol alone, the frequency of vomiting in the acupuncture group being less than half that in the controls.

Table II gives the data for the patients premedicated with nalbuphine. Acupuncture at the P6 point resulted in a significantly $(p<0.001)$ lower incidence of postoperative emetic sequelae compared with the control group. Sequelae were significantly less $(p<0.001)$ in patients given acupuncture at the P6 point than in those who received dummy acupuncture. There was no significant difference in the prevalence of emetic sequelae in patients having dummy acupuncture and those having no acupuncture.

In the group receiving nalbuphine patients who underwent acupuncture suffered less nausea. Among those who experienced no vomiting, 11 out of 19 in the control group and 12 out of 20 in the dummy acupuncture group were nauseated, compared with only three out of 22 receiving active acupuncture, the reduction in nausea being significant $(0.05>p>0.02)$.

There were no side effects attributable to acupuncture. The quality of anaesthesia and recovery was similar in all series and most patients were fully awake within three to 10 minutes of the end of anaesthesia.

\section{Discussion}

Acupuncture has been shown to reduce vomiting or nausea, or both, induced by two opioids with different emetic profiles. We have also shown this to be effective with $100 \mathrm{mg}$ pethidine.

In similar studies the incidence of postoperative nausea or vomiting, or both, has been shown to be around $20 \%$ in patients who received either atropine or diazepam premedication or who received no preoperative drugs. ${ }^{238}$ This is only slightly less than the $24 \%$ in the patients who received nalbuphine and acupuncture in our
TABLE I-Number of patients who experienced perioperative emetic effects among those premedicated with $100 \mathrm{mg}$ meptazinol who received acupuncture or no concurrent treatment

\begin{tabular}{lcccccccc}
\hline & \multicolumn{3}{c}{ Preoperatively } & & \multicolumn{3}{c}{ Postoperatively } \\
\cline { 2 - 3 } \cline { 7 - 8 } \cline { 7 - 8 } & Vomiting & Nausea & Neither & & Vomiting & Nausea & Neither \\
\hline No concurrent treatment & 16 & 5 & 4 & & 16 & 2 & 7 \\
Acupuncture & 6 & 9 & 10 & & 7 & 7 & 11 \\
\hline
\end{tabular}

* Vomiting=vomiting with or without nausea.

TABLE II-Number of patients who experienced vomiting or nausea in three groups of 25 patients premedicated with $10 \mathrm{mg}$ nalbuphine who received no additional treatment, acupuncture, or dummy acupuncture

No additional treatment Acupuncture Dummy acupuncture

\begin{tabular}{lrrr}
\hline Vomiting & 6 & 3 & 5 \\
Nausea & 11 & 3 & 12 \\
Neither & 8 & 19 & 8
\end{tabular}

* Vomiting=vomiting with or without nausea.

studies. The possibility that a longer period of stimulation or a direct current pulsator might reduce the incidence to that in the non-opiate series is being investigated.

We can offer no explanation for our findings. As nausea and vomiting were not mentioned to the patients a psychological effect is unlikely, and dummy acupuncture had no therapeutic effect. The unexpectedly high incidence $(88 \%)$ of emetic sequelae after treatment with meptazinol precluded the use of a dummy group with this drug, ${ }^{9}$ but even with this opioid we showed a reduction in sequelae for up to eight hours after five minutes of simple needling. Clearly, the potential of this non-toxic treatment should be explored in other fields.

Convincing studies with acupuncture as an analgesic are scarce as they are difficult to design and perform with acceptable control. ${ }^{10}$ We succeeded in avoiding the major pitfalls of clinical trials in this study. It is unknown whether acupuncture might be beneficial for, for example, patients receiving chemotherapy or radiotherapy.

We thank our gynaecological colleagues in the South Belfast hospitals for their cooperation in the study.

\section{References}

1 Patrick M, Eagar BM, Toft DF, Sebel PS. Alfentanil supplemented anaesthesia for short procedures. Br $\mathcal{F}$ Anaesth 1984;56:861-6.

2 Dundee JW, Moore J, Clarke RSJ. Studies of drugs given before anaesthesia. V: Pethidine $100 \mathrm{mg}$ alone and with atropine or hyoscine. Brf Anaesth 1964;36:703-10.

3 Dundee JW, Assaf RAE, Loan WB, Morrison JD. A comparison of the efficacy of cyclizine and perphenazine in reducing the emetic effects of morphine and pethidine. Br $\mathcal{f}$ Clin Pharmacol perphenazis: $1971-5$.

4 Lewith GT, Lewith NR. Modern Chinese acupuncture. Wellingborough: Thorsons, 1980.

5 Clarke RSJ, Dundee JW, Loan WB. The use of postoperative vomiting as a means of evaluating Clarke RSJ, Dundee JW, Loan WB. The use of
anti-emetics. Brf Pharmacol 1970;40:568-9.

6 Morrison JD, Hill GB, Dundee JW. Studies of drugs given before anaesthesia. XV: Evaluation of Morrison JD, Hill GB, Dundee JW. Studies of drugs given before anaesthesia. X
the method of study after 10,000 observations. Br f Anaesth 1968;40:890-900.

7 Dundee JW, Chestnutt WN, Ghaly RG, Lynas AGA. Reduction in the emetic effects of opioid preanaesthetic medication by acupuncture. Br f Clin Pharmacol 1986;22:214-5.

8 Dundee JW, Haslett WHK, Keilty SR, Pandit SK. Studies of drugs given before anaesthesia. XX: Diazepam-containing mixtures. Br $\mathcal{F}$ Anaesth 1970;42:143-50.

9 Chestnutt WN, Dundee JW. The influence of cyclizine and perphenazine on the emetic effect of meptazinol. European fournal of Anaesthesia 1986;3:27-32.

10 Lewith GT. Can we assess the effects of acupuncture? Br Med $f$ 1984;288: 1475-6.

(Accepted 11 fuly 1986) 